\title{
Change of Functional Requirements For Information Systems Integration With Internet of Things
}

\author{
Gabriela Mesnita \\ Alexandru Ioan Cuza University, Faculty of Economics and Business Administration, Department of \\ Business Information Systems, Iasi, Romania \\ gabriela.mesnita@feaa.uaic.ro
}

Received date: 30 September 2016; Accepted date: 12 December 2016;

Published date: 13 February 2017

Academic Editor: Klara Antlova

Copyright (C) 2017. Gabriela Mesnita. Distributed under Creative Commons CC-BY 4.0

\begin{abstract}
Nowadays there are some concepts that indicate a new revolution in information technology and systems. Internet of Things (IoT) is one of those which produce significant changes at information systems level. In this context, information systems developers are challenged with numerous practical and theoretical controversial topics on the adaptation of information systems to the IoT characteristics. Most studies approach the new issue from the architecture perspective and the infrastructure required for communication. But, there are few approaches about functional requirements, data streaming and data processing to be adapted to the Internet of Things. This is the aim of our paper. In that regard, we proceed to identify the state-of-the-arts in this field, based on literature review, and we use the modelling methods and field of expertise. Next, we will highlight the key features that should be mastered in order to integrate the IoT into information systems for the new synchronized enterprises. Moreover, this paper will emphasize the changes related to the functional requirements based on the general framework proposed. Most functional requirements aim to change the method of data gathering, processing and communication, recording information generated by business transactions and include data that have not been considered before by business systems as they were viewed as being the main elements of technical and engineer systems.
\end{abstract}

Keywords: Internet of things, functional requirements, information systems development, use case diagram

\section{Introduction}

At the end of the 90's, when the world of electronic business and electronic commerce was in full development, a new technology appeared aimed to support the value chain of businesses known under the name of the Internet of Things or Objects and put into practice especially using RFID. Although it appeared as a technology that

Cite this Article as: Gabriela Mesnita (2017), "Change of Functional Requirements For Information Systems Integration With Internet of Things ", Journal of Software \& Systems Development, Vol. 2017(2017), Article ID 361662, DOI: 10.5171/2017.361662 
seemed to be developing in the coming years, it did not happen in terms of applicability. Even if the RFID technology had been used on well-defined segments of business, it could not be applied on a large scale due to difficulties related to broad band communications, standardization of communication languages, web platforms and interoperability of systems, especially of the embedded systems. In addition, there also was the high cost of RFID tags, lack of devices, embedded software products for gathering, processing and communication of data in different formats, structured or unstructured. Also, there were difficulties due to the high volume of collected data. Therefore, from the wallmart symphony, things did not develop, as quickly as we had expected. So, starting with 2008-2010, together with the explosion of cloud technologies, platforms based on semantic web and ontology, the presence of the big data concept and large scale use of data analytics, business intelligence, pervasive computing, augmented reality, the Internet of Things became the Internet of Everything, even though the expression IoT has been kept. This is the reason why topics such as the impact, influence, advantages, disadvantages and challenges of the IoT on business information systems have been reactivated.

Most literature, as it has also been noted by other authors, investigates data communication, interoperability, security, system architecture (Zambonelli 2016), (Chen et al. 2014), (Matos et al. 2015), (Lee and Lee 2015), (Dar et al. 2015), but less the last layer of architecture, that of information systems and the integration of the IoT into company architecture.

So, we will move from a general architecture of the IoT to data processing, the new requirements by which information systems may use the IoT. The architecture from which we start our study is based on views of (Oprea 1999), (Cretu 2006), (Dospinescu and Perca 2011), (Fotache and Cogean 2013), (Dospinescu and Perca 2013), (Pavaloaia 2013), (Greavu-Serban 2015). Considering the changes generated by the integration of the
IoT into the architecture of a company, new terms have been used, such as sensing enterprises (Boza et al. 2016), generic enablers (Barmpounakisa 2015), smart enterprises (Fang et al. 2015), and we suggest the term connected and synchronized enterprises. These terms underline the challenges faced by enterprises through the IoT, data now attract objects and objects generate data requiring an integration and perfect synchronization of systems, objects and companies. New business models that companies have to adopt, the use of the IoT in different fields, the impact of the IoT upon information systems ask for proper solutions, so that data created benefits to users and not even bigger problems if they would not have adopted the IoT.

Studies by (Boza 2015), (Zambonelli 2016), (Chen et al. 2014), (Dar et al. 2015), (Fang et al. 2015), (Verdouw et al. 2015), (Meroni 2015) suggest that the focus has been mostly on the physical layer of connected equipment and objects, the integration of the IoT not being well-researched from the methodological and systematic perspective of information systems and business data and applications.

Therefore, we will identify, by means of use case diagrams, the requirements of the systems that ask for the attention of those involved in the development/adaptation of systems to the IoT. This will be done starting from the framework suggested for the interaction of the information system with external entities by means of its integration with the IoT.

So, we approach information systems in the context of the IoT from the following perspectives:

- Functional requirements induced by the IoT, starting from the features that the new systems should have;

- The most involved systems are the transaction processing systems, grouped by the main business processes and displayed by means of use case 
diagrams showing the points of connection of the system with the objects;

To interpret these two perspectives, we will shortly present the features of systems in the context of the IoT. Then, we will suggest the general framework of system interaction with external entities. It will be the support for the identification of functional requirements of information systems in the context of the IoT.

\section{Features of information systems integrated with IoT}

Most authors believe that we can find the applicability of the IoT in the following fields: construction, agriculture, health, electricity, transportation, and logistics (Mazhelis and Warma 2013), (Xu et al. 2014), (Houyou et al. 2012), (Vicente et al. 2015), (Havis 2014). Some examples of IoT used in information systems are:

- Information identification about where are is each product based on RFID tags. This generates an automatic update of inventory in the same time with product preparing for delivery;

- Activating ventilation and heating systems in food stores, based on temperature registered by sensors or actuators so temperatures can be maintained on suitable level, according to the storage conditions registered in RFID tag;

- Recording energy and other utilities costs, based on sensors and actuators;

- Automatic data gathering about humidity and activating irrigation systems, including plus the quantity of water used, time and periodicity so the system could learn about operation;

- Automatic optimization of transport routes based on traffic conditions through sensors and geographical information systems etc.

Based on the above, the authors agree that to exploit the facilities offered by the IoT, the information systems must have at least the following features:

Interoperability and compatibility (Fersi 2015), (Xu et al. 2014), (Zambonelli 2016), (Ebersold and Glass 2015) Taking into account the heterogeneity of various data sources, from RFID sensors to embedded software devices, the systems have to ensure data interaction, gathering, processing and communication, so that there do not appear problems in the running of processing procedures. Moreover, system development should take into account that other objects will connect to it that have not been identified yet. It means that communication protocols and data representations schemes are needed to identify objects connected to the system and that could be used to gather, process and transmit data irrespective of their type. The systems should be able to learn specific stereotypes as to ensure using self-adaptation and autoconfiguration that they can take over dynamically the data they need, send the data required by objects with which it can connect, synchronize all interconnected components.

This may be done only if we ensure the standardization of protocols and platforms to manage data. Also, it is important to have common semantics for concepts with which the IoT will operate to make possible the cooperation and communication among objects.

Scalability and Extensibility (Fersi 2015), (Xu et al. 2014), (Zambonelli 2016), (Houyou et al. 2012). Functionality must be provided to systems, irrespective of the number of connected objects. Globally, it is stated that there will be over 50 billion devices connected to the Internet and communicating among them. Clearly, an information system will not be interacting with all these devices but it is essential to ensure its stability and functionality so that it works efficiently regardless of the number of connected objects. It ensures and provides another feature of the system, effective operation on a global scale. 
Reliability (Xu et al. 2014), (Ahmad 2014). The systems must work without interruptions, except the scheduled ones. The more connected devices receiving and sending data, signals, information by many network structures, the harder it is to provide this feature. All connected elements become potential sources of interruptions in the system functionality. Traditional systems work in predictable environments, with stable networks, relational data bases, planned software updates and announced well in advance. They were not developed to function under unpredictable conditions, where various devices may be connected or disconnected at different times and the network may function at its highest capacity at one time and the signal may be very weak at another time. These aspects have a critical impact on non-functional requirements of the system that should be given special attention by developers.

Self-adaption and context awareness (Fersi 2015), (Ahmad 2014), (Ruiz-Lopez et.al 2013), (Namirimu 2015), (Xiao et al. 2014) are new features for traditional systems and basic for the systems of pervasive computing. In other words, the systems must be able to identify, analyze and react to changes in work environment, namely, have the ability to add, eliminate, replace services, procedures and processing processes, so as to be able to cope with the dynamic context and reach their goals. These features place developers into critical situations as these are nonfunctional requirements changing depending on the state of interconnected objects, being transversal complex requirements.

System trust (Fersi 2015), (Popescul and Georgescu 2013), (Rudy 2015), (Leister and Schultz 2012), (Sicari et al. 2015), taking into account that many software modules interacting among them have been developed by different teams, companies, having their own methodologies and interests. It is both a security feature and trust that the system functions as expected providing required information. Also, it can filter and send data depending on interconnections among objects.

Starting from these features, we believe that attention should be focused mainly on the self-notion (Haller et al., 2008) including: self-configuration, self-healing (automatic discovery and correction of faults), self-optimization (monitoring and automated control of resources to ensure optimal functioning of the defined requirements), and self-protection. In other words, we may state that we enter in the age of system selfies that go beyond picture-making.

System features must be assessed taking into account the types of connected objects to business and technical operations based on the following typology.

RFID is the initial technology of the IoT allowing automatic identification and gather of data using radio waves, tags and readers. There are three types of tags (Lee and Lee 2015) influencing communication with systems. Passive tags containing data about the tagged product or object are often used in supply, logistics, transportation and stock management operations. Active tags have been incorporated with external sensors by means of which various features of the environment may be measured, such as deposit temperature, atmospheric pressure, precipitation and humidity or the level of toxicity. Such tags are used in production processes, stocking and depositing operations, long-distance assets management. The third category is made of semi-passive tags containing microchips used to communicate data to readers. In terms of their relationship with the information system, tags can only send data to processing processes and cannot take over information from the system to activate specific actions or reconfigurations depending on the state of the system. It will be reflected in the context diagram by a single flow between the system and the RFID.

Sensors extend the boundaries of IT infrastructure to integrate devices, computers and machines with information 
systems based on communication standards (Mayberry 2005). The most common sensors are GPS, bar code sensors, sensors embedded in mobile devices, sensors calculating distances between two landmarks, proximity sensors, light-based and image-based sensors etc. (Che et al. 2014), (Kithion 2016a). Sensors communicate openly with several systems and the most important problem is to find a common language in order to take over data regardless the platform on which run the applications. Sensors, as well as RFID, send data to the system.

Actuators are used to activate and deactivate other devices or equipment based on information received from sensors or other systems. Consequently, we do not witness only data transmission depending on what tags and sensors identify but also the initiation of device or business operations functioning depending on the dynamics of recorded data. This is the reason why, in the context diagram, the relation with system is drawn by two flows, as to specifically emphasize the process of data communication and gather them. The actuators are one of the most complex objects having a direct impact on system functionality. Actuators together with sensors are the backbone of the IoT (Kithion 2016b).

Embedded software equipment with immediate access to sensed data and processed by the system (Mazhelis and Warma 2013). Having already incorporated the software solutions, the developers of information systems have to find the most efficient methods to ensure the compatibility and the interoperability of these equipments. Furthermore, it is important to focus on the ability to auto configure and self-adapt depending on the flows of data sent in both directions.

Recently, the objects/things have attained new features and this is the reason why they are called smart objects, including smart dust, viewed as autonomous elements able to communicate with external entities that may require information on the state of a smart object and may inform the smart object about the processes in which they are involved (Meroni 2015). These aspects also influence the system requirements.

Based on the above mentioned features and the typology of interconnected objects, we formulate the following two hypotheses of our research:

- In the development of information system integrated with the IoT, the most important challenges are related to network infrastructure, cloud services and capacity to adapt to processes of data gathering and filtering. Therefore, the most affected are the nonfunctional requirements. The network's role transforms from being a simple communication channel to incorporating elements required for configuration intelligence, scripts, policies, discovering and negotiating protocols (Houyou et al. 2012). But, this is not the aim of our study. Also, the functional requirements must be reconsidered in terms of data source identification, initiation of processing procedures and setting data destination, including types of user;

- The most affected transaction processing systems are production, inventory, sales and customers, purchasing and logistics. The impact on human resources and accounting is more indirect. All systems must integrate Business Intelligence, Big Data and Data Analytics as to fully benefit from the volume of data generated by the interconnected objects.

Apart from these two hypotheses, there is another one closely linked with the development of systems, the hypothesis related to data management. Therefore, the cycle of data processing undergoes big changes, especially related to data collection and making them ready for the processing. The aim is to assure the information system can cope with the big 
volume of data and ensure processing both business, operational transaction and data analytics type. However, this is the topic of a future research that must be approached in close connection with database management systems, Big Data and Data Analytics.

\section{General framework for the interaction of the IoT information system with external entities}

In the establishment of functional requirements presented in the next section, we started from the creation of a general framework of relations of the IoT with external entities. For this purpose, we used modelling methods for a generalized context diagram shown in Figure 1. The diagram has been built based on Yourdon\&DeMarco methodology. Besides the conventional symbols, to show specific features of new relations, especially of external entities with other components outside of system borders, we suggest an additional symbol (dotted line with an arrow at the end). Thus, we may easily observe the way in which the information system integrated with the IoT communicates with external entities, regardless whether these are traditional entities (departments, people, systems) or RFID, sensors, equipment belonging to a company or an environment outside it. To make the framework clearer, we used the parallel presentation of relations in the traditional system and the relations in the system integrated with the IoT.

A few explanations on external entities and relations in figure 1

For the traditional system, we decided that the category "Subunits" includes departments, production units, deposits and stores etc., namely the departments ensuring company operations. Under "Partners", we included both business partners, especially suppliers and customers, and the banks, public institutions and any other organization interacting with the company.

In what regards the IoT system, we kept those entities whose role does not change, whether because they interact in the same way with the system (Employees and the Management), or they lack the IoT, named Non-IoT. On the right side of the context diagram for information systems with IoT, we may observe connections only with the IoT entities that mainly send data and information both to the system and to entities owning the objects. These are RFIDs, sensors, actuators, software embedded machines owned by the company and partners. In this context, we may note on the two diagrams some aspects influencing the development of information system.

For the IoT environment, relations appear more often among systems with devices and objects interconnected within the company than among departments (we named them subunits), other applications and with traditional partners.

Non-IoT external entities are kept to ensure the interoperability of systems if partners or some subunits fail to integrate the IoT that grows the complexity of system development as the attention should be given to two directions, the IoT and non-IoT with data and information conversion

Systems users are not only people but also equipment, sensors which almost always send data to systems and other entities. Therefore, new requirements are not collected only from users-individuals and we should identify potential types of objects that will enter in contact with the system, the incorporated technology, used language, object's owner, types of sent data etc. As most objects are not known when systems and applications are developed, it is vital that self-configuration, selfidentification and self-adaptation features be provided.

When the system is designed, the focus will be put more on the design of system interface (Oprea, Dumitriu and Mesnita 2006) and less on user interface due to minimal human intervention in the relationship with the system. Many data flows are not visible any more to human users, nor data collection or the information sent as the interaction among 
the objects allows running operations automatically, the result visible to an individual being a delivered product, the initiation of device functioning, change of an environmental condition, a notification of a specific state etc.

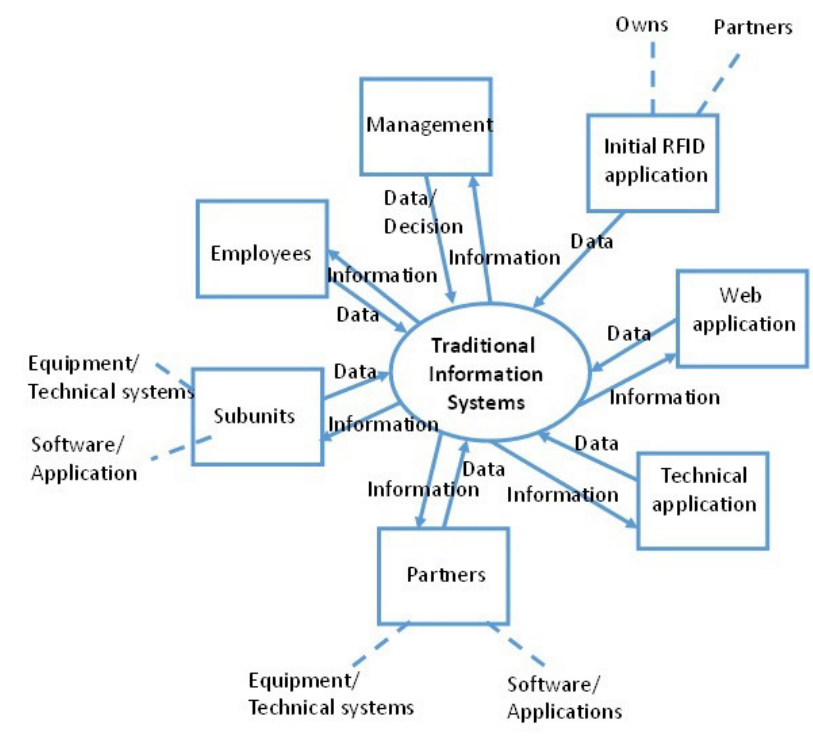

Context diagram for traditional information systems

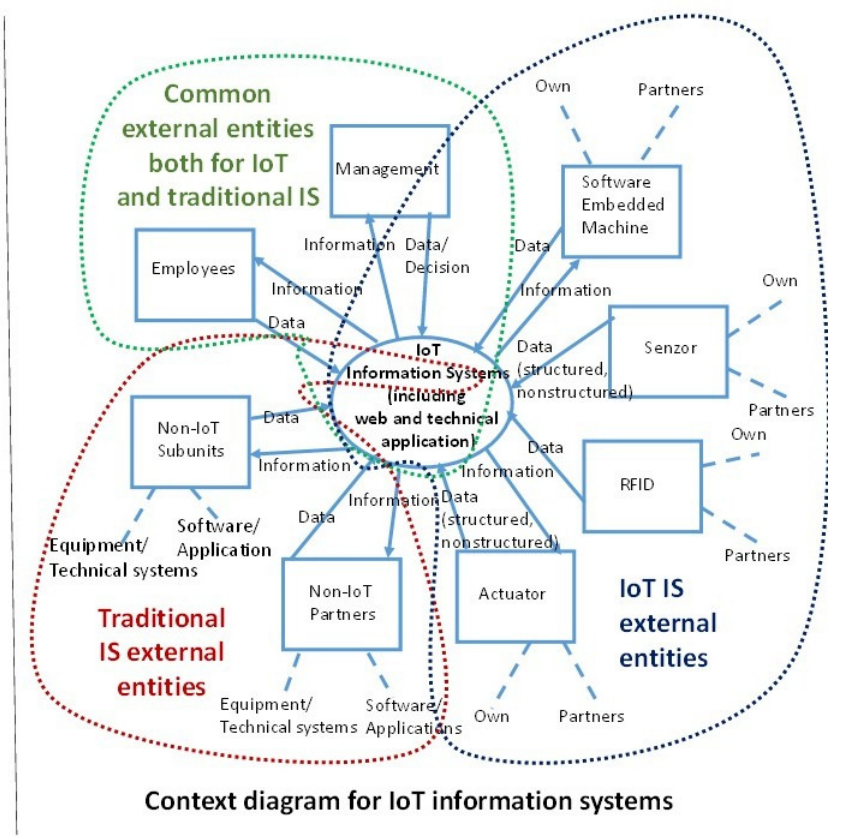

Figure 1: Context diagram for traditional information systems versus context diagram for information system with the IoT 
Most processing operations will be initiated automatically being mainly oriented towards external and state events (Oprea, Mesnita, and Dumitriu 2005). Processing operations begin to no longer be considered in real time, involving a lag time until the update is made, but they are dynamics with a visible immediate effect both on data and other objects.

Until now most information systems had interfaces for RFID, sensors, devices that existed in the company and only for specific conditions with those of business partners. So, most relations of systems with objects were set internally and for external relations there was an intermediary application to converse received or sent data through RFID, sensors and other devices.

Now, with the new IoT, things have changed as objects may connect among them or with people or machines with or without any internal restrictions, even automatically, without notification depending on system configuration. In this context, how the systems should react? How these should be developed so as, on the one hand, they benefit from the multitude of data needed for operations that in other conditions were difficult to collect, and, on the other hand, security risks and useless informational overload be limited? These are just a few questions that system developers should answer and then identify new requirements.

Based on these views, we may identify which components in the structure of system are affected by the integration with the IoT, establish data and information flows, method of data gathering, processing and communication by type of interconnected objects, operations and subunits that may be integrated with the IoT. This way, the existent applications may be assessed whether they may handle new flows of data and processing procedures or just need extensions or should be replaced. Finally, it should be checked if the security policy, business contracts and development strategies still meet the challenges of the IoT.

\section{New functional requirement for information systems in IoT}

As we have mentioned, the aim of our research was to identify the main functional requirements of information systems by the integration with the IoT based on literature, previous experience and the general suggested framework of information system interaction with external entities in the context of the IoT.

Depending on the area of applicability and the architecture of the IoT, there should be found a solution by means of which any interconnected object, regardless whether it is human-to-human, human-to-object, object-to-object, (Vicente et.al 2015), may be allowed to reflect in the information system the results of its interactions. To use fully the capacities of systems based on the IoT, a software infrastructure is needed supporting not only the connection of objects among them, but also providing to stakeholders and users the means to access data generated by the IoT and benefit from its advantages.

The development of new systems should be designed using a decentralized data processing strategy considering all objects connected to business operations, services and data processing, so that data sources be retained, from classical business operations to operations generated by sensors or the ones that have already been processed by smart objects (Haller et al. 2008).

To meet these needs, the systems must incorporate new requirements, the nonfunctional requirements being more researched in literature compared to the functional ones. In our research, we started from the definitions of requirements provided by Oprea, Mesnita and Dumitriu (2005). Functional requirements are operations performed by the system, namely, functions, processes and processing procedures as a response to business operations of a company. Nonfunctional requirements follow aspects related to hardware and software environment in which the system will be 
operating. They specify the system features, such as implementation restrictions, performance, reliance on a specific development platform, safety of exploitation etc.

From the most important non-functional requirements, we list the following:

- new communication protocols and data representation schemes providing the interaction among heterogeneous objects, other than those needed for unique identification of objects (Zambonelli 2016), (Dar et al. 2015)

- mechanisms used to discover, form and manage groups of objects so as to establish relations among objects, objects and humans and manage their operation (Zambonelli 2016);

- $\quad$ providing support for a typology of dynamic network that could be made using service-oriented type of architecture, especially to ensure optimal functioning of middleware layer (Lee and Lee 2015);

- existence of large data storage spaces and broadband communication channels to provide high speed processing and communication of big data (Lee and Lee 2015), including efficient solutions for back-up in real time for data generated by such a big number of devices and objects connected in real time. The following questions may be asked: Are back-ups still needed? Are these made in the same way as for traditional systems? What filters are used considering the huge volume of data generated by the interconnection of objects?

- data security and protection are important challenges, although sometimes these are exaggerated taking into account that these aspects have been addressed by specialists since the development of mobile and pervasive computing type of applications, namely, transition to web 2.0.

In what regards functional requirements, these may be differentiated by type of company activity, adopted development strategy, degree of integration of the IoT in business operations. However, some of them are common to all companies wishing to move to new technologies and others are similar to those identified in web-based systems. Out of them, we believe the most important are:

- Ensuring interaction through automated system interfaces among business partners as in the case of systems based on ecommerce and e-business (Verdouw et al. 2015);

- Ensuring automated monitoring and control of business operations, especially the operations connected to objects and smart devices so as to eliminate human intervention as much as possible and the system reacted in real time depending on processed data. Monitoring and control are extremely important especially in production, supply and checking the state of products and services (Verdouw et al. 2015), (Xu et al. 2013)

- Automated planning and scheduling of operations with dynamic adaptability of systems to changes generated by data sent by objects, so as to make possible data initiation, resource reallocation, production replanning etc.

- Ensuring distance service and maintenance using sensors measuring, recording and sending information about the state of products, equipment and carriage (Xu et al. 2013).

There have appeared new processing operations and those performed by traditional transaction processing systems are changing, some of them not requiring special attention as they had been implemented by moving to first systems 
connected to RFID and architectures based on web-services. So, according to Chen (Chen et al. 2014), middleware in the context of the IoT should have at least the following functionalities:

- $\quad$ Coordinating triggering devices for gathering and sending data using RFID, sensors, actuators, software embedded equipment;

- $\quad$ Filtering and aggregating data so that only really needed data will be processed;

- Routing and integrating data into information systems so all activities will be efficient;

- Monitoring and aggregating data to support decision-making.
For a more analytical view, table 1 presents a short list of the main requirements that should be considered in developing/adapting transactions processing systems through the IoT. The list was made using the grouping of systems around the main business functions of a company, according to (Oprea 1999), (Oprea and Mesnita 2002), (Airinei et al. 2014), (Fotache et.al. 2010): production, supply, logistics, inventory and transportation, sales and customers, human resources, accounting. For a better view, we will model the requirements with the use of case diagrams, providing examples for production that is probably mostly influenced by the IoT and supply and logistics as it reflects reversely the relation with customers and sales.

Table 1: Summary of requirements to change or add new processing operations into transactions processing systems using the IoT

\begin{tabular}{|c|c|c|}
\hline $\begin{array}{c}\text { Transaction processing } \\
\text { systems }\end{array}$ & $\begin{array}{l}\text { New processing } \\
\text { requirements }\end{array}$ & $\begin{array}{l}\text { Requirements to change } \\
\text { processing operations }\end{array}$ \\
\hline Production & $\begin{array}{l}\text { Recording manufacturing } \\
\text { conditions (temperature, } \\
\text { weather, humidity, } \\
\text { geographic area, } \\
\text { seasonality) } \\
\text { Recording the influence of } \\
\text { environment on product } \\
\text { quality } \\
\text { Automatic labelling of } \\
\text { product contents directly } \\
\text { during manufacturing } \\
\text { Dynamic calculation of costs } \\
\text { Automatic assessment of } \\
\text { equipment functionality }\end{array}$ & $\begin{array}{l}\text { Planning production flow } \\
\text { and needed resources } \\
\text { Automatic identification of } \\
\text { non-conforming products } \\
\text { Automatic recording of } \\
\text { defect causes } \\
\text { Automatic recording of raw } \\
\text { material, materials, package } \\
\text { quantity } \\
\text { Automatic notification about } \\
\text { the need to initiate the } \\
\text { process of equipment } \\
\text { maintenance }\end{array}$ \\
\hline $\begin{array}{l}\text { Supply, inventory, logistics } \\
\text { and transportation }\end{array}$ & $\begin{array}{l}\text { Automatic recording and } \\
\text { notification on conditions of } \\
\text { transportation and storage } \\
\text { Automatic initiation of } \\
\text { devices for transport and } \\
\text { storage ideal conditions } \\
\text { (cooling, heating, ventilation, } \\
\text { humidity etc.) } \\
\text { Reception without opening } \\
\text { the package/container from } \\
\text { the supplier } \\
\text { Inventory dynamic updating } \\
\text { Dynamic calculation of } \\
\text { needed inventory } \\
\text { Dynamic updating of car } \\
\text { fleet }\end{array}$ & $\begin{array}{l}\text { Automatic recording and } \\
\text { identification of the product } \\
\text { position } \\
\text { Automatic recording and } \\
\text { identification of } \\
\text { container/vehicle where the } \\
\text { product is located automatic } \\
\text { loading/unloading of } \\
\text { inventory } \\
\text { Inventory management of } \\
\text { loaded/unloaded products } \\
\text { or products transferred to } \\
\text { production } \\
\text { Automatic checking of } \\
\text { quality and quantity of } \\
\text { inventory products }\end{array}$ \\
\hline
\end{tabular}




\begin{tabular}{|c|c|c|}
\hline $\begin{array}{c}\text { Transaction processing } \\
\text { systems }\end{array}$ & $\begin{array}{l}\text { New processing } \\
\text { requirements }\end{array}$ & $\begin{array}{l}\text { Requirements to change } \\
\text { processing operations }\end{array}$ \\
\hline & $\begin{array}{l}\text { Dynamic calculation of } \\
\text { optimal storage areas }\end{array}$ & $\begin{array}{l}\text { Automatic optimization of } \\
\text { transport routes based on } \\
\text { traffic conditions, including } \\
\text { systems such as Uber } \\
\text { Automatic transmission of } \\
\text { orders to suppliers upon } \\
\text { inventory when decreased to } \\
\text { a certain level } \\
\text { Identification of product } \\
\text { status (pre-order, ready for } \\
\text { delivery, on delivery, } \\
\text { received, repaired etc.) }\end{array}$ \\
\hline Sales and customers & $\begin{array}{l}\text { Automatic labelling of } \\
\text { product delivery address } \\
\text { Dynamic following of } \\
\text { delivery without transport } \\
\text { operator intervention } \\
\text { Automatic issue of warranty } \\
\text { certificate } \\
\text { Following product usage } \\
\text { Customer notification on } \\
\text { different product operations } \\
\text { (repairs, service, } \\
\text { maintenance etc.) } \\
\text { Automatic notification on } \\
\text { possible recovery of } \\
\text { materials upon product } \\
\text { destruction } \\
\text { Automatic notification on } \\
\text { the waste use } \\
\text { Automatic blocking of } \\
\text { product use when it } \\
\text { becomes dangerous }\end{array}$ & $\begin{array}{l}\text { Notification on the expiry of } \\
\text { risk-free period of product } \\
\text { use } \\
\text { Automatic recording of } \\
\text { product receipt without } \\
\text { opening the package } \\
\text { Automatic recording of } \\
\text { returned products and the } \\
\text { causes } \\
\text { Dynamic calculation of } \\
\text { product price in a basket } \\
\text { Automatic recording of } \\
\text { invoice payment } \\
\text { Automatic recording of } \\
\text { user's behavior } \\
\text { Automatic setting of } \\
\text { consumer profile }\end{array}$ \\
\hline Human resources & $\begin{array}{l}\text { Dynamic planning of human } \\
\text { resources to optimize } \\
\text { production-sales cycle } \\
\text { Dynamic recording of human } \\
\text { resources costs per product } \\
\text { unit, execution phase and } \\
\text { performance } \\
\text { Reallocation of resources } \\
\text { based on operations }\end{array}$ & $\begin{array}{l}\text { Recording the interaction of } \\
\text { employees and equipment to } \\
\text { asses carried tasks } \\
\text { Dynamic recording of time } \\
\text { units needed to manufacture } \\
\text { a product, deliver a service } \\
\text { or execute a task, including } \\
\text { recording internal and } \\
\text { external influence factors } \\
\text { Automatic identification of } \\
\text { the best employee per each } \\
\text { position, level, task etc. }\end{array}$ \\
\hline Accounting & $\begin{array}{l}\text { Dynamic calculation of } \\
\text { reserves and provisions } \\
\text { Dynamic accounting } \\
\text { recording by assessing } \\
\text { "level" (assets, liabilities, } \\
\text { equity) variables and flow } \\
\text { (revenues, expenses, } \\
\text { income) variables for any }\end{array}$ & $\begin{array}{l}\text { Dynamic reporting of } \\
\text { information about company } \\
\text { operations } \\
\text { Recording in real time } \\
\text { (really in real time with no } \\
\text { delays) business } \\
\text { transactions through events- } \\
\text { based accounting }\end{array}$ \\
\hline
\end{tabular}




\begin{tabular}{|c|c|c|}
\hline $\begin{array}{c}\text { Transaction processing } \\
\text { systems }\end{array}$ & $\begin{array}{l}\text { New processing } \\
\text { requirements }\end{array}$ & $\begin{array}{l}\text { Requirements to change } \\
\text { processing operations }\end{array}$ \\
\hline & $\begin{array}{l}\text { period of time (Liu and } \\
\text { Vasarhely 2014) } \\
\text { Ensuring data comparability } \\
\text { over time } \\
\text { Auditing the entire set of } \\
\text { transactions and not only a } \\
\text { random sample } \\
\text { Automatic identification of } \\
\text { transactions viewed as } \\
\text { abnormal for company } \\
\text { operations } \\
\text { Notification and blocking } \\
\text { operations to prevent fraud } \\
\text { by scanning transactions for } \\
\text { different periods and times }\end{array}$ & $\begin{array}{l}\text { Identifying places, positions, } \\
\text { processes in a company that } \\
\text { have hidden, abnormal, } \\
\text { unforeseen or beyond } \\
\text { standards costs }\end{array}$ \\
\hline
\end{tabular}

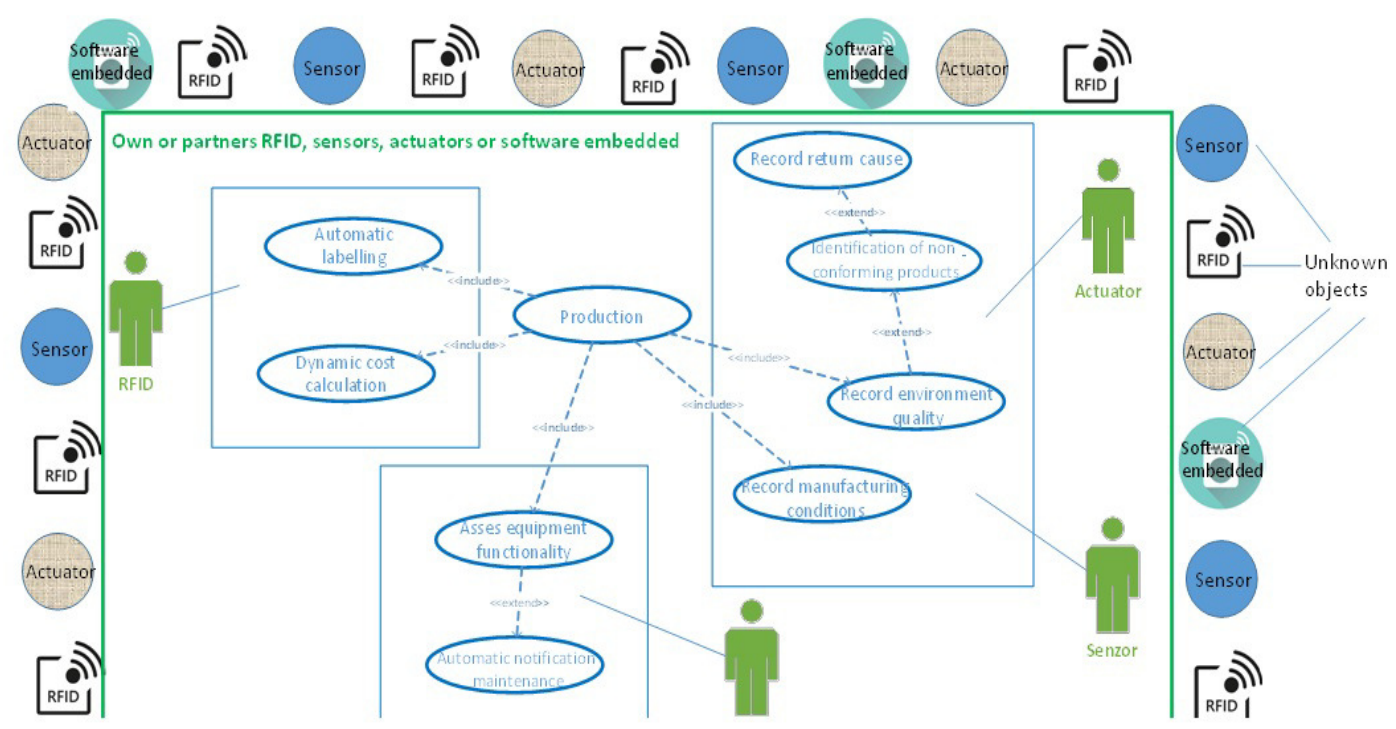

Fig. 2: Use case diagram of production system for new functional requirements 


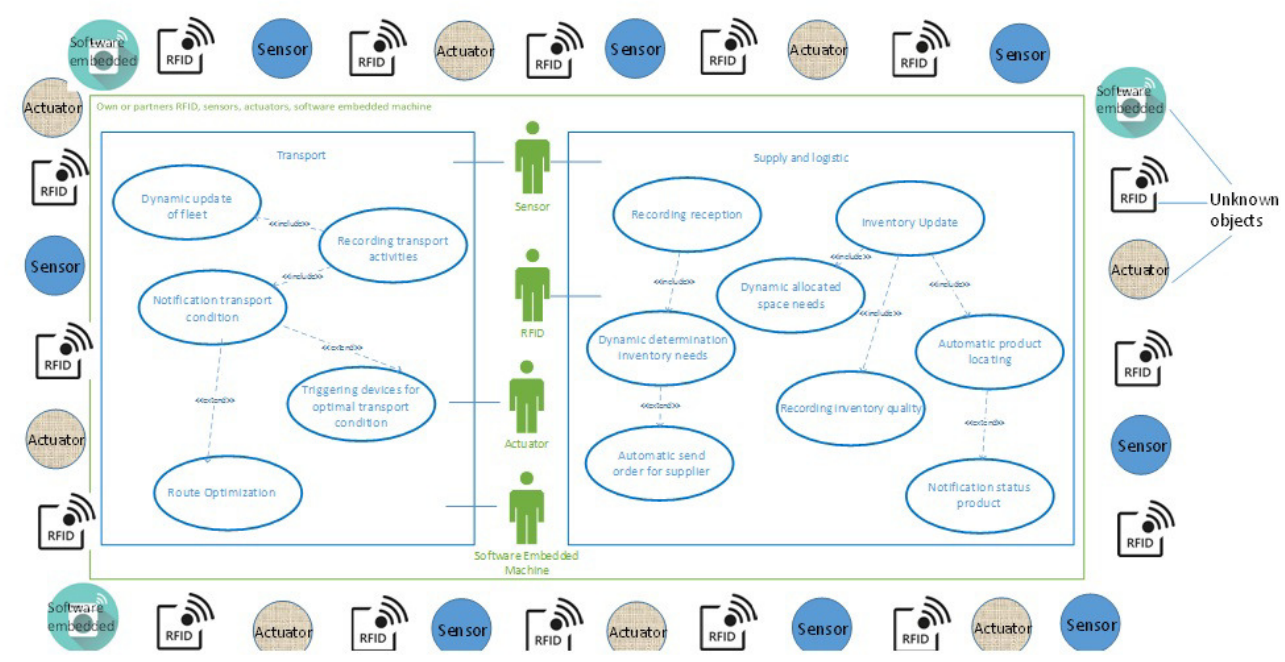

Fig. 3: Use case diagram of supply and logistic system for new functional requirements

As it may be noted, the most important changes in the nature of functional requirements appear in transaction recordings and in their auditing and reporting. Manual collection of primary data will be almost entirely eliminated leading to reduction of errors due to data manual recording. At first sight, the changes seem to be similar to those observed in the first forms of product automation and robotization and forms of data and money electronic transfer (EDI and EFT). However, it is more complex as now data source and their nature are different, as well as their format.

Cao and Zhu (Cao and Zhu, 2012) state most applications of the IoT are not in the area of finance, namely, business operations, quantifiable in money and affecting the assets, so three important questions appear for information systems:

- How the information will be stored on the IoT hardware?

- How technical information will be integrated into information from accounting?

- How the applications of the chain value will be managed centrally?
The business sector must be able to collect information through the IoT, especially using tags placed on inventory objects, on tangible assets, on certificates and bonds circulating on the bank and stock market, so that any time these items move, there will be no need to collect data manually. Data transfer may be done using XBRL by allocating a unique identification number for each asset and its transactions (Cao and Zhu 2012).

In conclusion, the information system in order to cope with changes and the need for self-adaptability should be organized in modules with highly reduced interdependence. In other words, the focus will be placed on the development of systems and applications with a reduced level of coupling and the SOA (Service Oriented Architecture) (Haller et al. 2008) linked with ROA (Resource Oriented Architecture) (Dar et al. 2015) seems to be an ideal model for such a need.

\section{Conclusions}

This study presents a general framework of information system interaction with external entities in the context of the IoT in order to establish new functional requirements. To define this framework 
and the new requirements, we reviewed the literature, used modelling methods and our previous experience in the analysis and design of information systems. The identified aspects, the discovered requirements and the provided argument may provide support to experts developing/adapting information systems integrated with the IoT.

Most functional requirements aim to change the method of data gathering, processing and communication, recording information generated by business transactions and include data that have not been considered before by business systems as they were viewed as being the main elements of technical and engineer systems.

With the appearance of the IoT, things have seriously changed so that we will need to talk about information systems without using the term business or technical as they need to be integrated without any separation borders. The main challenge remains the collection and quantification of non-monetary data, a possible solution being to have an events based-accounting management and the integration of block chain on a large scale.

Also, the teams developing systems will not be made up only of experts in business applications or engineers, but will be mixed teams as many interfaces of business applications will be interacting directly with objects, sensors, equipment for recording and sending data as it has been noted in use case diagrams in section 4 . Moreover, system requirements will no longer be identified just by talking to system users as individuals who require and send information due to the fact that the notion of user has now a new meaning reflected by objects and devices connected to the world of business.

The main limitation of the study lies in the lack of a quantitative and qualitative research validating of the newly identified requirements, on the one hand, and the general framework of system interaction with external entities on the other hand. These limitations are new lines of research that have been already announced in the previous section, namely, the influence of the IoT on data processing cycle.

\section{References}

1. Ahmad, M. (2014). 'Reliability Models for the Internet of Things: A Paradigm Shift', Software Reliability Engineering Workshops (ISSREW), [Online], 2014 IEEE International Symposium on, Naples, 2014, pp. 52-59, [Retrieved November 22, 2015], http://ieeexplore.ieee.org/stamp/stamp.js $\mathrm{p}$ ?tp $=$ \&arnumber $=6983801$ \&isnumber $=69$ 83760

2. Airinei, D. et al. (2014), Tehnologii informationale aplicate în organizatii, Editura Universitatii Alexandru Ioan Cuza, Iasi, pp. 110-116.

3. Barmpounakisa, S et al. (2015), 'Management and control applications in Agriculture domain via a Future Internet Business-to-Business platform',[Online], Information Processing in Agriculture Volume 2, Issue 1, May 2015, Pages 51-63, [Retrieved July 16, 2016] http://www.sciencedirect.com/science/art icle/pii/S2214317315000153

4. Boza, A., Cortes, B., del Mar Eva Alemany, M., Cuenca, L. (2016), 'Conceptual framework, for applying internet of things in production systems for sensing enterprises', [Online] Brazilian Journal of Operations \& Production Management 13 (2016), pp. 66-71, [Retrieved July 16, 2016]

https://bjopm.emnuvens.com.br/bjopm/ar ticle/view/V13N1A7

5. Cao, H., Zhu, Z. (2012), 'Research on Future Accounting Information Systems in the Internet of Things Era. A Information Flow Framework Based on Event Accounting', [Online], 2012 IEEE International Conference on Computer Science and Automation Engineering, [Retrieved July 16, 2016)https://www.researchgate.net/publi cation/261113128_Research_on_future_ac 
counting_information_system_in_the_Inter net_of_Things_era

6. Chen, S-L., Chen, Y-Y/. Hsu, C. (2014), 'A New Approach to Integrate Internet-ofThings and Software-as-a-Service Model for Logistic Systems: A Case Study, [Online], Sensors 2014, 14, [Retrieved February 22, 2015], www.mdpi.com/journal/sensors

7. Cretu, L. (2006), 'Enterprise Engineering - A New Organizational Discipline' (1), [Online], Revista Informatica Economica, nr. 3(39)/2006, pp. 57-63, [Retrieved November 20, 2015] http://revistaie.ase.ro/content/39/Cretu_L iviu_v2.pdf

8. Dar, K., Taherkordi, A., Baraki, H., Eliassen, F., Geihs, K. (2015), 'A resource oriented integration arhitecture for the Internet of Things: A business process perpective', [Online], Pervasive and Mobile Computing 20 (2015) 145-159, [Retrieved February 2, 2016], http://www.sciencedirect.com/science/art icle/pii/S1574119214001862

9. Dospinescu, O., Perca, M. (2011), 'Technological Integration For Increasing The Contextual Level of Information', [Online], Analele Stiintifice ale Universitatii "Alexandru Ioan Cuza" din Iasi - Stiinte Economice, vol. 58, pages 571-581, [Retrieved November 20, 2015] http://anale.feaa.uaic.ro/anale/resurse/inf o2dospinescuo.pdf

10. Dospinescu, O., Perca, M. (2013), 'Web Services in Mobile Applications', [Online], Informatica Economica vol. 17, no. 2/2013, pp. 17-26, [Retrieved November 20, 2015] http://www.revistaie.ase.ro/content/66/0 2\%20-\%20Dospinescu,\%20Perca.pdf

11. Ebersold, K., Glass, R. (2015), 'The Impact of Disruptive Technology: The Internet of Things', [Online], Information Systems, Vol. 16 Issue 4, pp. 194-201, [Retrieved March 3, 2016], http://www.iacis.org/iis/2015/4_iis_2015 _194-201.pdf
12. Fang, S., Zhu, Y., Xu, L., Zhang, J., Zhou, P., Luo, K., Yang, J. (2015), 'An integrated system for land resources supervision based on the IoT and cloud computing', [Online], Enterprise Information Systems, [Retrieved January 14, 2016], http://www.tandfonline.com/doi/abs/10. 1080/17517575.2015.1086816

13. Fersi, G. (2015), 'Middleware for Internet of Things: A Study', [Online], DCOSS '15 Proceedings of the 2015 International Conference on Distributed Computing in Sensor Systems, pp. 230-235, [Retrieved March 3, 2016], http://dl.acm.org/citation.cfm?id=286031 6

14. Fotache, D., Hurbean, L., Dospinescu, O., Pavaloaia, V.D. (2010), Procese organizationale si integrare informationala. Enterprise Resource Planning, Editura Universitatii Alexandru Ioan Cuza, Iasi, pp. 25-76.

15. Fotache, M., Cogean, D. (2013), 'NoSQL and SQL Databases for Mobile Applications. Case Study: MongoDB versus PostgreSQL', [Online], Informatica Economica vol. 17, no. 2/2013, pp. 41-58, [Retrieved November 20 , 2015], http://revistaie.ase.ro/content/66/04\%20 -\%20Fotache,\%20Cogean.pdf

16. Greavu-Serban, V. (2015), 'Cloud computing Caracteristici și modele', Colectia Cercetare avansata postdoctorala in stiinte economice, Editura ASE Bucuresti, 2015, p. 36

17. Haller, S., Karnouskos, S., Schroth, C. (2008), 'The Internet of Things in an Enterprise Context', [Online], Chapter Future Internet - FIS 2008, Volume 5468 of the series Lecture Notes in Computer Science pp 14-28, [Retrieved November 20, 2015]

http://link.springer.com/chapter/10.1007 \%2F978-3-642-00985-3_2 
18. Havis, M. (2014), 'Don't Underestimate the Impact of the Internet of Things', [Online], Forbes - Internet of Things (IoT), [Retrieved November 20, 2015], http://www.forbes.com/sites/mikekavis/ 2014/07/21/dont-underestimate-theimpact-of-the-internet-ofthings/\#2c26f4399253

19. Houyou, A.M., Huth, H-P., Trsek, H., Kloukinas, C., Rotondi, D. (2012), 'Agile Manufacturing: General Challenges and an IoT@Work Perspective', [Online], Conference: 17th IEEE International Conference on Emerging Technologies and Factory Automation (ETFA 2012), [Retrieved March 3, 2016], https://www.researchgate.net/publication /234661014_Agile_Manufacturing_General _Challenges_and_an_IoTWork_Perspective

20. Hu, F., Xie, D., Shen, S. (2013), 'On the Application of the Internet of Things in the Field of Medical and Health Care', [Online], Conference: Green Computing and Communications (GreenCom), 2013 IEEE and Internet of Things (iThings/CPSCom), IEEE International Conference on and IEEE Cyber, Physical and Social Computing, [Retrieved Janyary 14, 2016], https://www.researchgate.net/publication /261208276_On_the_Application_of_the_In ternet_of_Things_in_the_Field_of_Medical_a nd_Health_Care

21. Kithion, B. (2016a), 'Sensors in IOT', [Online], [Retrieved on August 16, 2016], https://learniot.wordpress.com/2016/03/ 28/sensors-in-iot/

22. Kithion, B. (2016b), 'Actuators in IOT', [Online], [Retrieved August 16, 2016], https://learniot.wordpress.com/2016/03/ 29/actuators-in-iot/

23. Lee, I., Lee, K. (2015), 'The Internet of Things (IOT): Applications, investments, and challenges for enterprises', [Online], Business Horizons 58, 431-440, [Retrieved February 2, 2016], http://www.sciencedirect.com/science/art icle/pii/S0007681315000373
24. Leister, W., Schulz, T. (2012), 'Ideas for a Trust Indicator in the Internet of Things', [Online], SMART 2012: The First International Conference on Smart Systems, Devices and Technologies, [Retrieved January 14, 2016], https://thinkmind.org/download.php?artic leid=smart_2012_2_10_40043

25. Liu,Q., Vasarhelyi, M.A. (2014), 'Big Questions in AIS Research: Measurement, Information Processing, Data Analysis, and Reporting', [Online], Journal of Information Systems, Spring 2014, Vol. 28, No. 1, pp. 117, [Retrieved November 20, 2015], http://aaajournals.org/doi/pdf/10.2308/i sys- 10395

26. Matos, E., Amaral, L.A., Tiburski, R., Lunardi, W., Hessel, F., Mareczak, S. (2015), 'Context Aware Systems for Information Services Provision in the Internet of Things', [Online], 2015 IEEE 20th Conference on Emerging Technologies \& Factory Automation (ETFA), Luxembourg, pp. 1-4, [Retrieved July 16, 2016], http://ieeexplore.ieee.org/document/7301 624/?arnumber $=7301624$

27. Mayberry, R. (2005), 'Beyond RFID, A new era of wireless sensors', [Online], IoT Agenda, Tech Target, [Retrieved August 16, 2016],

http://searchmobilecomputing.techtarget.c om/feature/Beyond-RFID-A-new-era-ofwireless-sensors

28. Mazhelis, O., Warma, H. et al. (2013), 'Internet-of-Things Market, Value Networks, and Business Models: State of the Art Report', [Online], Computer Science And Information Systems Reports, Technical Reports Tr-39, Jyväskylä University Printing House, Jyväskylä, Finland, [Retrieved November 18, 2015], http://www.internetofthings.fi/extras/IoT SOTAReport2013.pdf

29. Meroni, G. (2015), 'Integrating the Internet of Things with Business Process Management: A Process-aware Framework 
for Smart Objects', [Online], CEUR WORKSHOP PROCEEDINGS, [Retrieved January 14, 2016], http://hdl.handle.net/11311/964025

30. Namirimu, V. (2015), 'User Requirements for Internet of Things (IoT) Applications - An Observational Study', [Online], Thesis MGSE-2015-03, Faculty of Computing, Karlskrona, Sweden, [Retrieved January 14, 2016], http://www.divaportal.se/smash/get/diva2:873960/FULLT EXT03.pdf

31. Oprea, D. (1999), Analiza si proiectarea sistemelor informationale, Editura Polirom, Iasi, 1999, p. 92-93.

32. Oprea, D., Mesnita, G. (2002), Sisteme informationale pentru manageri, Editura Polirom, Iasi, pp. 22-51.

33. Oprea, D., Mesnita, G., Dumitriu, F. (2005), Analiza sistemelor informationale, Editura Universitatii Alexandru Ioan Cuza, Iasi, pp. 301-303.

34. Oprea, D., Dumitriu, F., Mesnita, G. (2006), Proiectarea sistemelor informationale, Editura Universitatii Alexandru Ioan Cuza, Iasi, pp. 65-67.

35. Pavaloaia, V.D. (2013), 'Methodology Approaches Regarding Classic versus Mobile Enterprise Application Development', [Online], Informatica Economica vol. 17, no. 2/2013, pp. 59-72, [Retrieved November 20, 2015], http://revistaie.ase.ro/content/66/05\%20 -\%20Pavaloaia.pdf

36. Popescul, D., Georgescu, M. (2013), 'Internet Of Things-Some Ethical Issues', [Online], The USV Annals of Economics and Public Administration Volume 13, Issue 2(18), pp. 208-214, [Retrieved January 14, 2016],

http://seap.usv.ro/annals/ojs/index.php/a nnals/article/viewFile/628/599
37. Rudy, G. (2015), 'Developers need to establish trust in the IoT', [Online], [Retrieved January 14, 2016], http://embedded-

computing.com/articles/developers-needto-establish-trust-in-the-iot/

38. Ruiz-López, T. et al. (2013), 'ContextAware Self-adaptations: From Requirements Specification to Code Generation', [Online], Chapter in Ubiquitous Computing and Ambient Intelligence. Context-Awareness and Context-Driven Interaction, Volume 8276 of the series Lecture Notes in Computer Science pp 4653,[Retrieved January 14, 2016] http://link.springer.com/chapter/10.1007 \%2F978-3-319-03176-7_7

39. Sicari, S. et al. (2015), 'Security, privacy and trust in Internet of Things: The road ahead', [Online], Computer Networks, Vol. 76, January 2015, [Retrieved January 14, 2016],

http://www.sciencedirect.com/science/art icle/pii/S1389128614003971DOI:10.1016 /j.comnet.2014.11.008

40. Verdouw, C.N., Robbemond, R.M. , Verwaart, T., Wolfert, J., Beulens, A.J.M. (2015), 'A reference architecture for IoTbased logistic information systems in agrifood supply chains, Enterprise Information Systems', [Online], [Retrieved July 7, 2016] http://www.tandfonline.com/doi/pdf/10. 1080/17517575.2015.1072643

41. Vicente, J., Fitzsimons, V. et al. (2015), 'IT@Intel Exploring the Internet of Things in the Enterprise', Intel White Paper Internet of Things, [Retrieved August 4, 2015],

http://www.intel.com/content/www/us/e $\mathrm{n} /$ it-management/intel-it-bestpractices/exploring-the-internet-of-thingsin-the-enterprise-paper.html

42. Xiao, G., Guo, J., Xu, L.D., Gong, Z. (2014), 'User Interoperability With Heterogeneous IoT Devices Through Transformation', [Online], IEEE Transactions On Industrial Informatics, Vol. 
10, No. 2, May 2014, [Retrieved January 14, 2016],

http://ieeexplore.ieee.org/stamp/stamp.js p?arnumber $=6742587$

43. Xu, L. D., He, W., Li, S. (2014), 'Internet of Things in Industries: A Survey', [Online], IEEE Transactions on Industrial Informatics 10(4):2233-2243, November 2014, DOI: 10.1109/TII.2014.2300753, [Retrieved 45.
December 2, 2015], https://www.researchgate.net/publication /270742269_Internet_of_Things_in_Industr ies_A_Survey

44. Zambonelli, F. (2016), 'Towards a General Software Engineering Methodology for the Internet of Things', [Online], [Retrieved May 8, 2016], https://arxiv.org/pdf/1601.05569.pdf 